and International Conference Art, Illustration and Visual Culture in Infant and Primary Education
Blucher Education Proceedings March 2015, Number 2, Volume 1

\title{
La serigrafía: alta y baja tecnología
}

Susana Jodra mariasusana.jodra@ehu.es

Usoa Fullaondo usoa.fullaondo@ehu.es

Universidad del País Vasco, España

\section{Reference}

Jodra, Susana; Fullaondo, Usoa; (2012) "La serigrafía: alta y baja tecnología", p. 229-234 . In: Barbosa, Helena; Quental, Joana [Eds]. Proceedings of the 2nd International Conference of Art, Illustration and Visual Culture in Infant and Primary Education. São Paulo: Blucher, 2015. ISSN 2318-695X, ISBN: 978-989-98185-0-7 DOI 10.5151/edupro-aivcipe-44

Resumen

La serigrafía no es sólo un sistema de reproducción, también es un medio de creación artística con amplios recursos plásticos y materiales. Aunque sus antecedentes y aplicaciones industriales la relegaron durante años a esta categoría, no son pocos los ilustradores y artistas de diferentes ámbitos que han utilizado este procedimiento como medio de expresión. Como técnica de impresión, resulta necesario conocer los diferentes procesos de clisado de la pantalla, cómo estampar, sobre qué y con qué, pero con una base mínima resulta posible adaptar el medio a las necesidades individuales. Además, la variedad de motivos y soportes sobre los que es posible estampar, así como la combinación con otras técnicas de impresión analógicas y digitales, hacen de la serigrafía un medio de creación muy versátil e interesante. En la pantalla se pueden clisar o acotar los motivos para la impresión de ediciones, pero también cabe la posibilidad de intervenir directamente sobre ella para crear monotipos. Si bien el clisado fotomecánico requiere de una infraestructura muy concreta y permite la reproducción fiel de todo tipo de motivos, el clisado manual directo e indirecto posibilita la simplificación del proceso, así como la reducción de los recursos materiales necesarios. De esta manera, una vez reducida la infraestructura, utilizando tintas de base acuosa de fácil elaboración e inocuas adaptadas al soporte específico, con una regleta y una pantalla, cualquiera puede estampar casi en cualquier lugar.

Palabras clave serigrafía, tecnología, creación.

\section{Abstract}

Screen printing is not only a reproduction system, it 's also a way of artistic creation with great plastic resources and materials. Although its historical causes and industrial applications have pushed screen printing into the background, a lot of illustrators and artists have used this technique as a way of expression for many years. As any other printmaking techniques, the knowledge of different ways of creating a stencil and how to print is fundamental to know which substrate you may use and how you should do it; however, a minimum understanding is enough to adapt the medium to individual requirements. Besides, the variety of motives and substrates you can print on, as well as the combination with other analogical and digital printing techniques, turn the screen printing into an interesting and flexible way of creation. You can stencil or delimit the motives in the screen for the printing of editions; moreover, you can take part directly in the creation of monotypes. Using a direct coating photomechanical stencil requires precise equipment but gives the possibility of creating a faithful reproduction of several motives. If the image is transferred to the screen manually the process is simpler and reduces the investment costs. Consequently, once you have reduced the infrastructure, using easily made water based inks adapted to specific supports, and making use of a squeegee and a screen, everyone can print almost everywhere. 
$2^{\text {nd }}$ International Conference Art, Illustration and Visual Culture in Infant and Primary Education de Arte, llustracão e Cultura Visual

na Educação Infantil e Primária

\section{Introducción}

Si hablamos de pintar o dibujar todos sabemos a que nos referimos, incluso si hablamos de fotografía, medio que podríamos denominar de alta tecnología, conocemos el o los procedimientos técnicos básicos para ejecutarlos. Pero si hablamos de técnicas gráficas, grabado e impresión, el desconocimiento es notable. Él término nos puede resultar ajeno y aún más las técnicas, materiales y procesos que engloba.

Si bien en origen estas técnicas fueron el recurso para editar y sustituir la copia de textos de manera manual, y posteriormente la ilustración manual, en la actualidad éstas han sido remplazadas en muchos ámbitos por la impresión digital y los sistemas de impresión automatizados. Sin embargo es en el terreno de creación artística en general donde las técnicas tradicionales (grabado calcográfico, xilografía, litografía), las no tan tradicionales (serigrafía, offset) junto con los nuevos soportes (planchas de poliéster, fotopolímeros, etc) sobreviven, se han adaptado, complementando y evolucionado.

Casi sin darnos cuenta, las nuevas tecnologías se han ido introduciendo en nuestras vidas y en nuestros modos de hacer. Con la idea de simplificar procesos y agilizar el trabajo, lograr más en menos tiempo. Proporciona tantos efectos que en ocasiones el artificio de los motivos resultantes es delirante y repetitivo, carente de interés. Tal y como indica Martin Salisbury "Es importante recordar que el ordenador es simplemente una herramienta más, tan buena como la persona que lo usa" (Salisbury, 2004).

También John Dawson refiriéndose a las nuevas tecnologías dentro del grabado y la impresión dice "(...) la tecnología actual ha abierto, indiscutiblemente, nuevos panoramas, estimulando la imaginación. No, obstante vale la pena recordar que la técnica es sólo un vehículo para las ideas, y que debe realzarlas no dominar sobre ellas" (Dawson, 1996)..

El acercamiento a unas técnicas o herramientas desconocidas requiere de un aprendizaje, el cual puede ser más o menos complejo. A posteriori, la disponibilidad de las mismas, con sus peculiaridades procedimentales y materiales, es lo que determina el continuar con un medio u otro. Resulta sencillo acceder a un ordenador, programas, cámaras digitales, etc., ocupan relativamente poco espacio, pero para trabajar con las técnicas de impresión es necesario una determinada infraestructura, materiales y espacio.

En el caso de la serigrafía, tema que nos ocupa, resulta una técnica interesante, además de por su versatilidad plástica en cuanto a materiales y soportes imprimibles, por la capacidad de simplificar considerablemente el proceso para adaptarlos a las posibilidades, tanto económicas como de espacio, del usuario. Consideramos necesario reivindicar su aplicabilidad en la ilustración, así como sus valores pedagógicos en la enseñanza. Podemos hablar de una vuelta a los orígenes recurriendo conscientemente a la baja tecnología.

\section{Fundamentos técnicos de} la serigrafía
En las diferentes técnicas gráficas se diferencian dos partes del proceso de trabajo, el grabado de la imagen de la matriz y la estampación o impresión de la misma. En la serigrafía o impresión permeográfica el proceso de estampación es siempre el mismo, mientras que el de grabado del motivo, en este caso denominado clisado, varía.

La impresión serigráfica se fundamenta en forzar el paso de la tinta, con la ayuda de una regleta o rescleta, a través de una malla de poliéster tensada sobre un marco que conforma la pantalla. La tinta atravesará las zonas de imagen que están abiertas, mientras que las de no-imagen se bloquean. La acción de estampar, en el caso de la serigrafía plana, es posible realizarla de forma manual casi en cualquier lugar. Basta con fijar el marco de madera de la pantalla mediante bisagras a un tablero o una mesa. 
$2^{\text {nd }}$ International Conference Art, Illustration and Visual Culture in Infant and Primary Education
Congresso Internacional

de Arte, llustracão e Cultura Visual

na Educação Infantil e Primária
Figura 1. Herramientas básicas. Pantalla con clisado fotomecánico, regleta y sistema de bisagra. Fuente: propia,2009

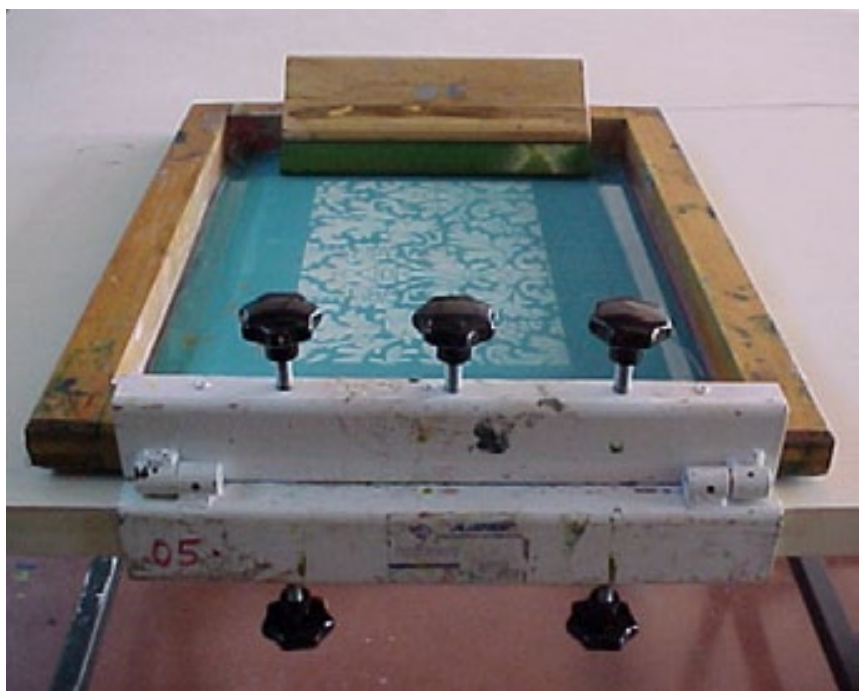

Sin embargo, a la hora de clisar o acotar el motivo en la pantalla es posible hacerlo de manera manual directa o indirecta, o de manera fotomecánica también directa e indirecta, e incluso combinada. Tanto en los sistemas manuales (baja tecnología) como fotomecánicos (alta tecnología) en el clisado directo el material utilizado penetra en el tejido, mientras que en el indirecto éste se prepara fuera de la pantalla. La serigrafía es conocida como medio ideal para estampar planos de color de manera uniforme, pero también por la posibilidad de reproducir imágenes fotográficas (sistema fotomecánico) y por la diversidad de tintas y superficies susceptibles de ser impresas (papel, tejidos, vidrio, plástico, cerámica, etc.).

Para el clisado fotomecánico se necesita una infraestructura y unos materiales muy concretos, como una insoladora y productos químicos, mientras que para el clisado manual no hace falta ningún equipamiento específico.

La serigrafía, técnica originariamente aplicación industrial, durante la gran depresión de 1929, en Estados Unidos supuso la tabla de salvamento para artistas e impresores. Bajo el lema Makework se impartieron cursos de formación y surgió el movimiento New Deal, lo que permitió a muchos de ellos sobrevivir mediante la edición de carteles propagandísticos y publicitarios, decoración textil, así como la edición de obra artística a bajo coste.
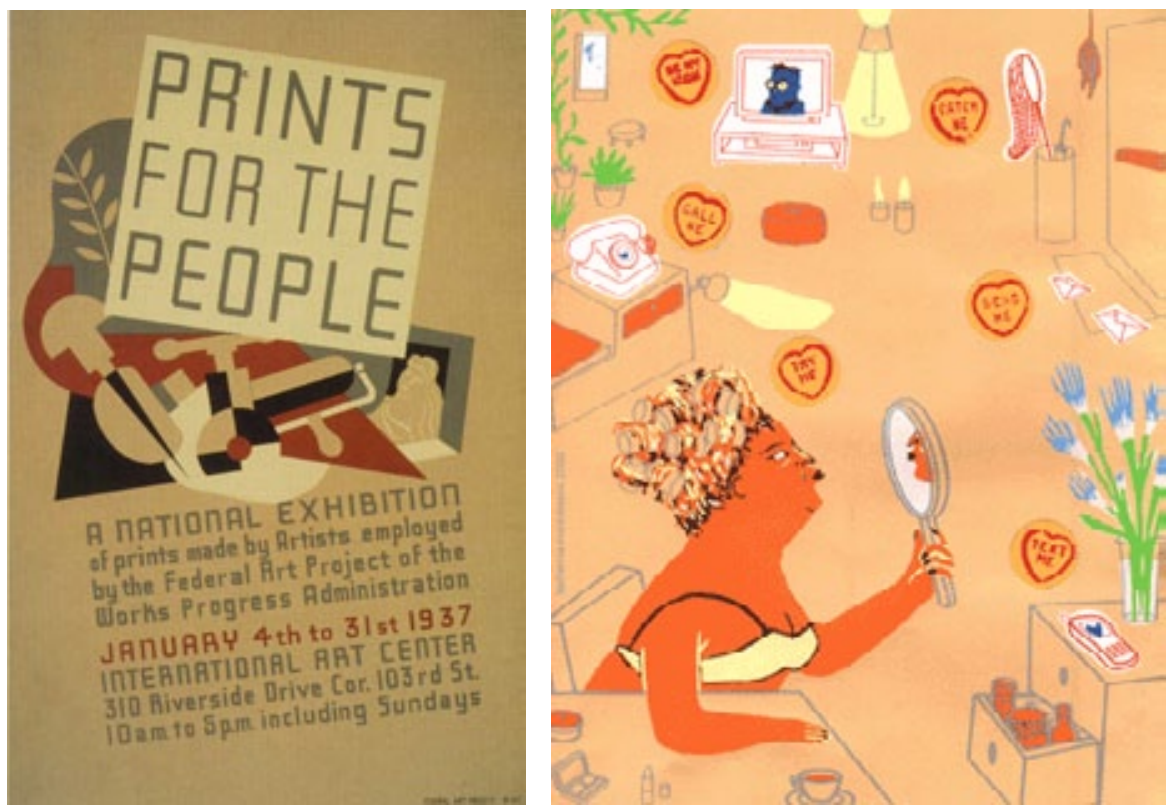

Figura 1. Richard Hall, Prints for the People, 1937. Fuente: Grabowski, B. y Fick, B., 2009

Figura 2. Katherina Manolessou. Lámina del libro de Artista It's Love, 2002 Fuente:www.lemoneyed.com 
$2^{\text {nd }}$ International Conference Art, Illustration and Visual Culture in Infant and Primary Education
Según fue evolucionando, viendo las nuevas posibilidades de éste, artistas como Andy Warhol o Robert Rauschenberg han utilizado la serigrafía de manera muy diferente en sus obras, pero generalmente como recurso para incluir la imagen fotográfica en sus composiciones. La mayoría de los ilustradores que utilizan la serigrafía se decantan por la reproducción fotomecánica, pero dado lo arduo del proceso, no suelen aplicarla en sus ilustraciones, pero sí en la edición de libros álbum o de artista, así como en la impresión de carteles.

\section{Reducir la tecnología y simplificar el proceso}

Figura 4. Clisado manual directo con plantilla de papel y estampación con témperas. Facultad de Bellas Artes, EHU/UPV. Fuente propia (2007)
Simplificar el proceso no significa crear imágenes de inferior calidad. Como ya se ha mencionado anteriormente, con una pantalla, una regleta y la tinta adecuada al soporte, es posible estampar en casi cualquier lugar. Incluso para el proceso fotomecánico es posible elaborar una insoladora de manera artesanal, pero la adquisición de emulsión fotográfica, recuperador de pantallas, disolventes y limpiadores, complican el proceso considerablemente.

Se trata por lo tanto de simplificar el modo de acotar o clisar el motivo en la pantalla y reducir la tecnología necesaria. Una de las posibilidades es utilizando plantillas. Estas se pueden realizar en papel de folio o en acetato para fotocopiadora. Para asegurar una impresión de contorno nítido, el material seleccionado debe ser lo más fino posible, pero a la vez resistente frente a las tintas al agua. La calidad de la imagen resultante vendrá determinada por la destreza de cada uno a la hora de cortar plantillas. Se trataría de partir de una imagen o motivo a todo color, hacer una separación de colores y sacar las fotocopias necesarias, una por color. Recortar la zona de imagen correspondiente a cada color de cada copia. Es decir, por cada color que componga la imagen se deberá realizar una plantilla, recomendando siempre el superponer los colores, frente a intentar encajarlos, y estampar de claros a oscuros; aunque esto es opcional.

Para estampar es suficiente con colocar la plantilla debajo de la pantalla y entintar o estirar la tinta por toda la superficie de la pantalla. Por efecto de la humedad de la tinta, al presionar contra a plantilla, ésta se adhiere totalmente a la malla, estampándose sobre el soporte definitivo solamente la imagen abierta en la plantilla recortada. Este sistema tiene la ventaja de que incluso los elementos recortados que quedan sueltos (islas) también se fijan en el lugar correspondiente, sin la necesidad de mantenerlos unidos al resto de la plantilla.
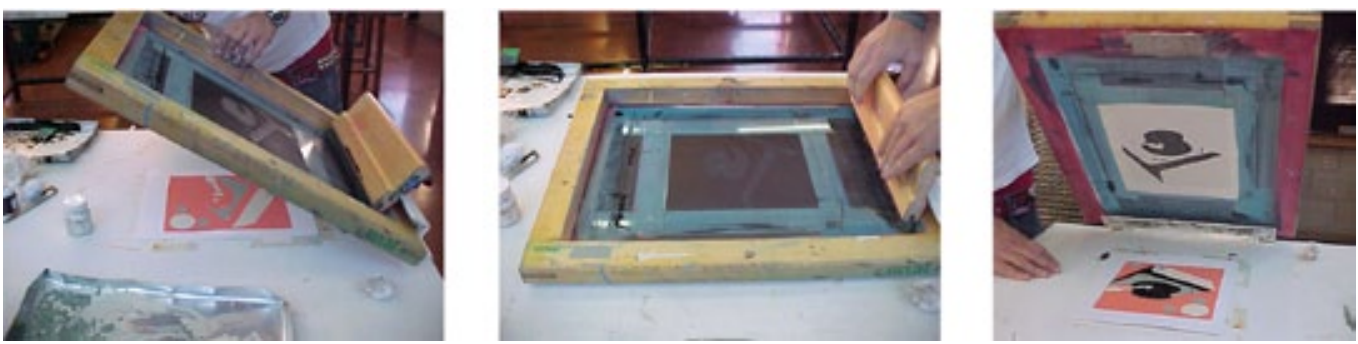

Es de señalar que uno de los principales problemas de la impresión serigráfica es el secado de la tinta en la pantalla. Utilizando tintas a base de temperas o guache y un medium con glicerina, basta con humedecer el interior de la pantalla con la ayuda de una esponja, para volver a abrirla.

Al partir de un motivo matriz, éste es susceptible de ser reproducido cuantas veces se desee, o según la vida útil de la plantilla, en cuyo caso se podría hacer una tirada. Sin embargo, pintando directamente sobre la pantalla se pueden realizar estampas únicas o monotipos e incluso series.

También es posible bloquear la pantalla utilizando simple cinta adhesiva o vinilos delicadamente recortados con el plotter de corte; combinando la alta y la baja tecnología. Existen otros métodos manuales de clisado directos, en el que el material de bloqueo penetra en la malla, pero resultan más problemáticos que el arriba descrito. 
2nd International Conference Art, Illustration and Visual Culture in Infant and Primary Education $2^{\circ}$ Congreso Internaciona

Arte, llustración y Cultura Visual en Educación Infantil y Primaria
${ }^{\circ}$ Congresso Internacional

de Arte, Ilustração e Cultura Visual

na Educação Infantil e Primária

\section{Recursos plásticos y pedagógicos}

Partiendo de la utilización de plantillas de papel y de tintas a base de témperas, el proceso de impresión serigráfico está libre de todo riesgo para la salud y el medio ambiente.

En la educación primaria el conocimiento de de los procesos de impresión permite desarrollar capacidades compositivas mediante la repetición y la seriación. Un mismo motivo puede ser impreso variando su color y ubicación, pero también en su relación con otras imágenes o elementos superponiéndolo, imprimiéndolo de manera parcial o total, saturándolo de tinta, yuxtaponiéndolo, etc. Utilizando y adaptando estos recursos de impresión es posible variar la composición y por tanto la lectura final.

También se desarrollan capacidades cooperativas, ya que varios alumnos o toda una clase pude participar en un mismo proyecto. Se ayudan unos a otros a la hora de crear las plantillas y también a la hora de estamparlas. Así mismo, se fomenta el trabajo en equipo, organizando, pactando y acordando donde imprimir cada elemento.

Si bien en las aulas se ha venido trabajando con sellos y plantillas, lo que supone una aproximación a la impresión en relieve y a la propia impresión permeográfica, estos recursos resultan bastante limitados.

Por otra parte, una de las grandes ventajas de la utilización de matrices, en este caso el motivo clisado en la pantalla, es la posibilidad de experimentar y también la de equivocarse. Existe un amplio espacio para el error y para cometer fallos. Al tener el motivo en la pantalla, siempre se podrá repetir aprendiendo de los errores.

Por ejemplo, un ejercicio útil es la impresión de pósters o carteles de gran formato de manera conjunta. Con pantallas tamaño tipo folio, muy manejables y sin necesidad de fijarlas a la mesa, los participantes intervienen creando composiciones diferentes pero conteniendo los mismos motivos. O la ilustración de una narración mediante el formato de leporelo o libro despegable.

Naturalmente, si se dispone de pantallas y regletas suficientes para cada alumno y alumna, también se podrán elaborar trabajos mucho más complejos, dependiendo de la edad, e incluso abordar la estampación de camisetas.

En el caso de los ilustradores, utilizando no sólo el bloqueo manual sino la impresión directa de monotipos, pintando directamente sobre la pantalla con materiales magros como lápices acuarelables o pasteles, es posible la creación desde planos de color, dibujos, transparencia e infinitas texturas.

La serigrafía es una técnica de impresión que ofrece amplias posibilidades plásticas, tanto a nivel creativo como pedagógico. La simplificación del proceso la convierte en un medio accesible a todo aquel que esté interesado en iniciarse en la técnica, en utilizar sus diversos recursos o en aplicarlos en las aulas.

Tal y como se ha mencionado, las ventajas de la serigrafía son varias. Es una técnica sencilla de aprender y de practicar. Es posible reducir y simplificar la infraestructura, herramientas y materiales. Con una pantalla, la regleta, la tinta al agua adecuada y cartulinas se puede ser muy creativo.

Es una técnica relativamente económica. Las tintas y los disolventes comercializados son los materiales más caros, pero al ser al agua y elaborarlas de manera artesanal partiendo de productos tan conocidos y asequibles como las temperas, se ahorra mucho. Además, si se secan en la pantalla o alguien se mancha con ellas, se eliminan fácilmente simplemente con agua. Esto agiliza enormemente el trabajo. Ni que decir tiene que al utilizar tintas al agua beneficia a todos: resulta seguro, no afecta a las personas que estén trabajando en el mismo espacio, se reducen los residuos y no se daña el medio ambiente.

Por otra parte, las regletas y pantallas se pueden hacer, pero si se compran, en breve se amortiza y rentabiliza el gasto, ya que son reutilizables. El espacio en el que practicarlo puede ser un aula, cuyo único requisito sea disponer de agua corriente. 
2nd International Conference Art, Illustration and Visual Culture in Infant and Primary Education $2^{\circ}$ Congreso Internacional Arte, Ilustración y Cultura Visual en Educación Infantil y Primaria $2^{\circ}$ Congresso Internacional de Arte, llustração e Cultura Visual na Educação Infantil e Primária

La viabilidad técnica y plástica de esta técnica es muy amplia y sencilla. Quizá lo más difícil de la serigrafía sea explicar en que consiste solamente mediante palabras, sin un apoyo visual.

\section{Referencias bibliográficas}

Adam, R. \& Robertson, C (2003). Screenprinting. The complete water-based system. London: Thames \& Hudson

Dawson, J. (1982). Guía completa del grabado e impresión. Técnicas y materiales. Madrid: Tursen / H. Blume ediciones (1996)

Grabowski, B. y Fick, B. (2009). El Grabado y la Impresión. Guí completa de técnicas, materiales y procesos. Barcelona: Art Blume, S.L.

Ingram, S. (2003). El ABC de la Serigrafia. Barcelona: Ricard Casals Consultantants, SA

Jodra Llorente, S. (2005). Análisis y Elaboración de Tintas de Base Acuosa para la Práctica Serigráfica. Aplicaciones plásticas y pedagógicas. Bilbao: Servicio Editorial de la Universidad del país Vasco EHU/ UPV

Salisbury, M. (2004). Ilustración de Libros Infantiles. Cómo crear imágenes para su Publicación. Barcelona: Editorial Acanto (2005)

Slade, C. (1998). Enciclopedia de Técnicas de llustración. Barcelona: Editorial Acanto, S.A.

Stromquist, A. (2004). Simple Screenprinting. Basic techniques \& creative projects. New York: Lark Books Tobella Soller, J. (2002). Técnica y Práctica del Proceso Serigráfico. Madrid: AEDES

Flynn Johnson, R. (2001).Artists' books in de modern era 1870-2000. San Francisco: The Fine Arts Museum 